\title{
Strength analysis of connecting rods with pistons using finite element method
}

\author{
Andoko ${ }^{1, *}$, Nanang Eko Saputro ${ }^{2}$ \\ ${ }^{1}$ Department of Mechanical Engineering, Engineering Faculty, Universitas Negeri Malang, 65145 \\ Malang, Indonesia.
}

\begin{abstract}
A connecting rod is the core component of an engine which has a function to transmit power released from combustion from the piston to the crankshaft. Deformation is the most commonly occurring damage to connecting rods. The connecting rods made of structural steel, aluminium alloy and titanium alloy were designed using Autodesk Inventor and analysed using ANSYS. The simulations showed the following results. The connecting rod made of structural steel had the highest maximum stress of 82.791 MPa. The connecting rod made of aluminium alloy had the highest maximum deformation of $0.84071 \mathrm{~mm}$. The three connecting rod materials had the same maximum safety factor, i.e. 15 .
\end{abstract}

\section{Introduction}

According to [1], a piston in petrol combustion engine serves to convert petrol into heat which eventually becomes mechanical power. A connecting rod is one of the most significant components that has a function to transmit the power to the crankshaft to run the engine.

The mechanical translational motion of a piston may cause damage to connecting rods. Deformation is the most commonly occurring damage. The magnitude of deformation experienced by connecting rods varies depending on material properties, size, and force received describes. The possible causes of failures in connecting rods are varied; some of which are hardness of the connecting rod and crank pin, distance between the connecting rod and crank pin bearing beyond the specified limit, high stresses at the critical area, design of the connecting rod, and lack of lubricating oil at the sliding interfaces [2].

[3] also stated that connecting rod damage may cause accidents and disruptions as often caused by low material strength, improper design and so forth. Moreover, [4] explained that connecting rods are generally made of steel, but titanium or aluminium based composites are more commonly used recently. [5] conducted a study to analyse connecting rod damage in depth. The damage was analysed through chemical analysis, hardness test, metallographic analysis, and tensile test. According to [6], the FEA analysis is a work simulation that provides insight into the behaviour of connecting rod components under loading in terms of stress, deformation, and safety factors. Materials used for making connecting rods are structural steel, aluminium alloy, and titanium alloy. The damage

\footnotetext{
*Corresponding author: andoko.ft@um.ac.id
} 
analysis was performed using ANSYS Workbench 15, and the connecting rods were designed using CAD software called Autodesk Inventor.

\section{Literature Review}

\subsection{Connecting Rod}

A connecting rod is a mechanical component that converts the reciprocating motion of piston into the rotational motion of crankshaft [5]. This component undergoes a complex state of stress, which includes the compressive stress due to gas combustion and the tensile stress in a moving component due to inertial forces.

[7] also stated that a connecting rod is a rod subjected to complex loading conditions. It carries high cyclic loads of $10^{5}$ to $10^{9}$ cycles, including high compressive loads due to combustion and high tensile loads due to inertial forces. Thus, the durability of the components is highly important.

As explained by [8], energy is transferred from piston to crankshaft via a connecting rod. During the process, the connecting rod translates the alternating motion into the rotational motion. The connecting rod consists of connecting rod body, cap, bolts, bearings and so on.

The end of the connecting rod connected to the piston pin is called the small end, while the one attached to the crankshaft is termed as the big end. Crankshaft rotating at high speed inside the big end causes a rise in temperature. The use of metal in the big end is particularly important to avoid that condition. The metal is lubricated with oil, and some of the oil is sprinkled from the oil hole to the inside of the piston to cool the plunger or piston. Along with the crank, this system forms a simple mechanism that converts linear motion into circular motion.
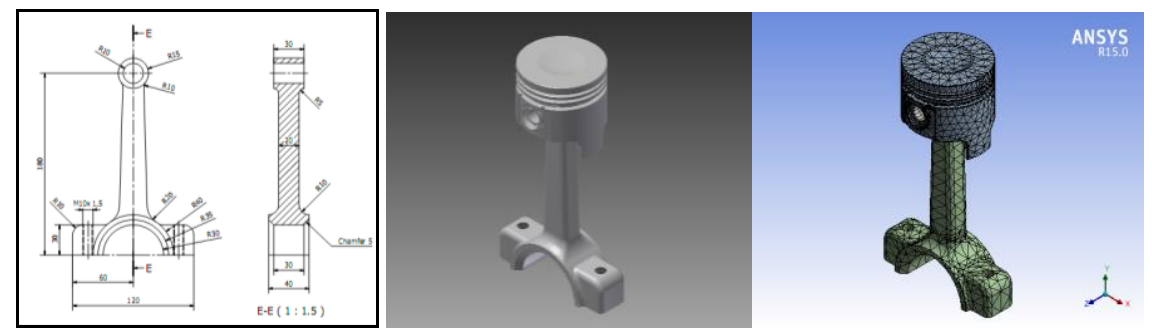

Fig. 1. Connecting rod dimensions

Figure 1. shows the dimensions of the connecting rod created using Autodesk Inventor. 


\subsection{Failure of Forklift Forks}
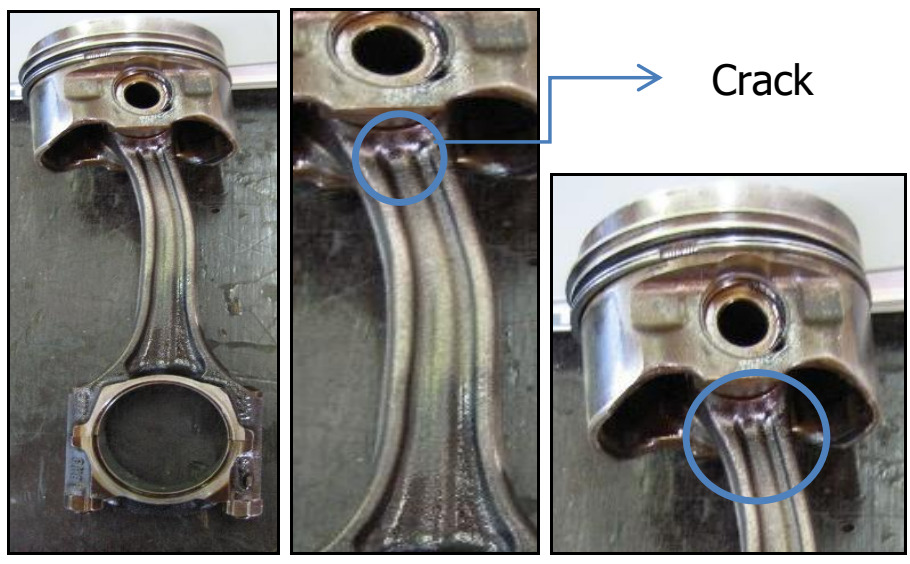

Fig. 2. Connecting rod failure due to buckling and crack propagation

Figure 2 shows the damage occurring to the connecting rod which caused by improper loading. Deformation occurred to the piston, making it bent. This damage resulted in a significant decrease in the performance of the connecting rod.

\section{Processing and Method}

Finite element analysis (FEA) was conducted on each connecting rod to investigate its stress, deformation, and safety factor. This type of analysis provides a way to conduct easy and efficient research on various parameters used with design and manufacturing conditions which are easily evaluated.

\subsection{Model Construction}

Table 1 shows the properties of some commonly used materials for making a connecting rod, i.e. structural steel, aluminium alloy, and titanium alloy.

Table 1. Connecting Rod Materials

\begin{tabular}{|c|l|c|c|c|}
\hline \multirow{2}{*}{ No } & \multirow{2}{*}{ Material Property } & \multicolumn{3}{|c|}{ Value } \\
\cline { 3 - 5 } & & Structural Steel & Aluminium Alloy & Titanium Alloy \\
\hline $\mathbf{1}$ & Density & $7850 \mathrm{Kg} / \mathrm{m}^{3}$ & $2770 \mathrm{Kg} / \mathrm{m}^{3}$ & $4620 \mathrm{Kg} / \mathrm{m}^{3}$ \\
\hline $\mathbf{2}$ & Young's modulus & $2 \mathrm{E}+11 \mathrm{~Pa}$ & $7.1 \mathrm{E}+10 \mathrm{~Pa}$ & $9.6 \mathrm{E}+10 \mathrm{~Pa}$ \\
\hline $\mathbf{3}$ & Poisson's ratio & 0.3 & 0.33 & 0.36 \\
\hline
\end{tabular}

As suggested by [4], titanium and aluminium based composites were selected for making the connecting rods, in addition to steel. The data of the material properties were obtained from Engineering Data in ANSYS Workbench.

\subsection{Simulation}


Each connecting piston was analysed using ANSYS Workbench for various measures, i.e. stress, deformation, and safety factor. The damage analysis included meshing of connecting rod. The meshing was done to determine the value at each point of the connecting rod. This process generated a mesh with 42736 nodes and 23111 elements. In addition, a fixed support and force are two crucial elements to conduct a load simulation of connecting rod. A fixed support was attached to the big end of the connecting rod bearings. Forces of $5000 \mathrm{~N}, 1050 \mathrm{~N}$ and $600 \mathrm{~N}$ were applied. The geometry of the connecting rod was adjusted to the materials selected, i.e. structural steel, aluminium alloy, and titanium alloy. The results of the analysis of stress, deformation and safety factor were obtained using the tools of ANSYS.

\section{Result and Discussion}

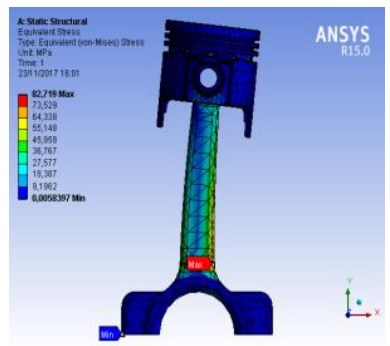

(a) structural steel

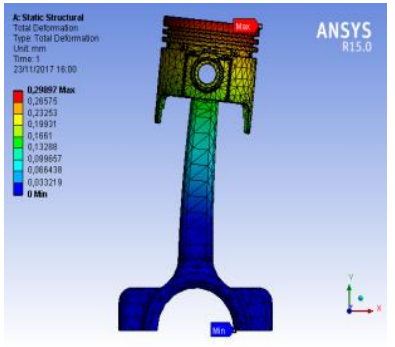

(b) aluminium alloy

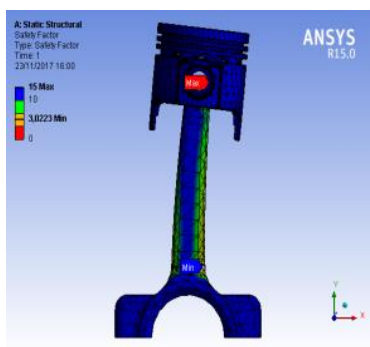

(c) titanium alloy

Fig. 3. Stress simulation of connecting rods

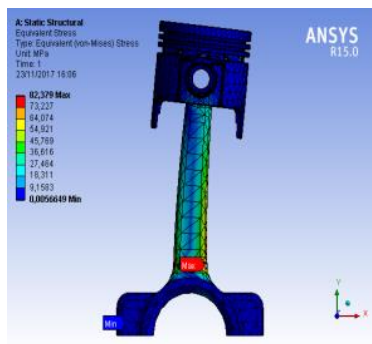

(a) structural steel

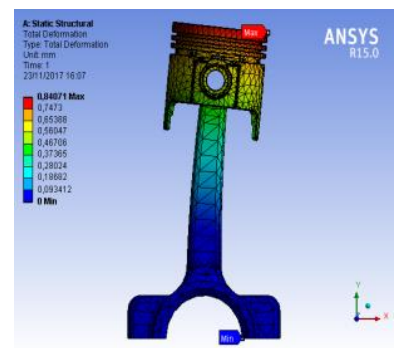

(b) aluminium alloy

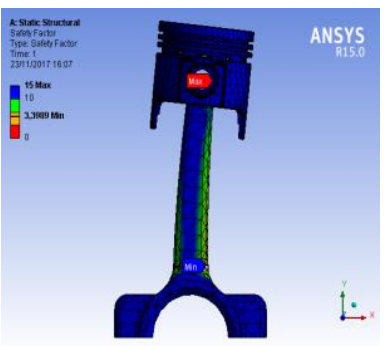

(c) titanium alloy

Fig. 4. Deformation simulation of connecting rods

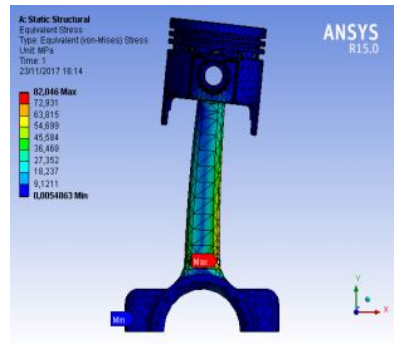

(a) structural steel

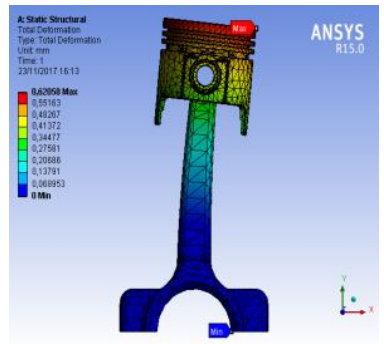

(b) aluminium alloy

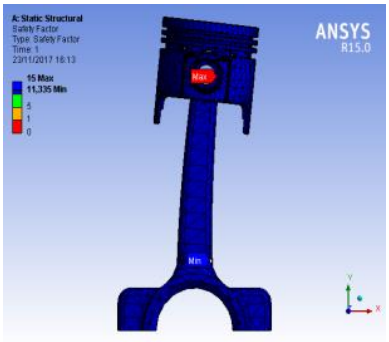

(c) titanium alloy

Fig. 5. Safety factor simulation of connecting rods 


\subsection{Stress, deformation, and safety factor}

The results of stress simulation showed that the connecting rod made of structural steel had maximum stress of $82.791 \mathrm{MPa}$ and minimum stress of $0.0058397 \mathrm{MPa}$ (see Figure 4a). The connecting rod made of aluminium alloy had maximum stress of $82.379 \mathrm{MPa}$ and minimum stress of $0.0056649 \mathrm{MPa}$ (see Figure $4 \mathrm{~b}$ ). The connecting rod made of titanium alloy had maximum stress of $82.046 \mathrm{MPa}$ and minimum stress of $0.0054863 \mathrm{MPa}$ (see Figure 4c).

\subsection{Deformation}

As shown in Figure 5a, the deformation occurring in the connecting rod made of structural steel was $0.29897 \mathrm{~mm}$. The deformation occurring in the connecting rod made of aluminium alloy was $0.84071 \mathrm{~mm}$ (see Figure 5b). The deformation occurring in the connecting rod made of titanium alloy was $0.62058 \mathrm{~mm}$ (see Figure $5 \mathrm{~b}$ ).

\subsection{Safety factor}

The results of safety factor simulation of connecting rods are presented in Figure 5. The connecting rod made of structural steel had a maximum value of 15 and a minimum value of 3.0223 (see Figure 6a). The connecting rod made of aluminium alloy had a maximum value of 15 and a minimum value of 3.3989 (see Figure 6b). The connecting rod made of titanium alloy had a maximum value of 15 and a minimum value of 11.335 (see Figure 6c).

\section{Conclusions}

A connecting rod is the core component of an engine which has a function to transmit power released from combustion from the piston to the crankshaft. Deformation is the most commonly occurring damage to connecting rods. The simulation results of the three connecting rod materials are as follows:

Table 2. Simulation results of connecting rods

\begin{tabular}{|c|l|c|c|c|c|c|c|}
\hline \multirow{2}{*}{ No } & \multirow{2}{*}{ Material } & \multicolumn{2}{|c|}{ Stress $(\mathrm{MPa})$} & \multicolumn{2}{c|}{ Deformation $(\mathrm{mm})$} & \multicolumn{2}{c|}{ Safety Factor } \\
\cline { 3 - 8 } & & Max. & Min. & Max. & Min. & Max. & Min. \\
\hline 1 & Structural Steel & 82.719 & 0.0058397 & 0.29897 & 0 & 15 & 3.0223 \\
\hline 2 & Aluminium Alloy & 82.379 & 0.0056649 & 0.84071 & 0 & 15 & 3.3989 \\
\hline 3 & Titanium Alloy & 82.046 & 0.0054863 & 0.62058 & 0 & 15 & 11.335 \\
\hline
\end{tabular}

The connecting rod made of structural steel had the highest maximum stress of 82.791 $\mathrm{MPa}$. The connecting rod made of aluminium alloy had the highest maximum deformation of $0.84071 \mathrm{~mm}$. The maximum safety factor of the three connecting rod materials was the same, i.e. 15 .

The authors acknowledge to State University of Malang for Hibah Penelitian PNBP UM 2018 with contract number 2.3.144/UN32.14/LT/2018. 


\section{References}

1. F. Wijayanti dan D. Irwan, J. Ilm. Tek. Mesin, 2(1), 34-42, (2014)

2. S. Khare, O. P. Singh, K. B. Dora, dan C. Sasun, Eng. Fail. Anal., 19, 77-86 (2012)

3. B. He, G. Shi, J. Sun, S. Chen, dan R. Nie, "Engineering Faiure. Analalysis, 34, 443450 (2013)

4. B. Nandish, K. P. Muthanna, dan M. B. Kaveriappa, Appl. Mech. Mater., 867, 228232 (2016)

5. C. Juarez, F. Rumiche, A. Rozas, J. Cuisano, dan P. Lean, Case Stud. Eng. Fail. Anal., 7, 24-31 (2016)

6. M. M. Andrei, N. Gheorge, R. M. Lonut, B. Mihai, dan H. L. Lulian, Appl. Mech. Mater., 657, 725-729 (2014)

7. M. M. Ali dan M. Haneef, dipresentasikan pada 4th International Conference on Materials Processing and Characterization, 2, 2094-2103 (2015)

8. C. Gang, W. Lei, W. Long, dan X. Peiqing, Appl. Mech. Mater., 722, 120-124 (2015) 